\title{
1625, o Fogo e a Tinta: a batalha de Salvador nos relatos de guerra
}

\section{5, Fire and Ink: Salvador battle in the war reports}

\section{CarlosZiller Cameniezki Gianriccardo G rassia Pastore}

Conformedebatido hátempos, etambém verificado diretamenteem inúmeras experiências coletivas, todo conflito vive sua versão resgesta e sua versão rerum getarum. ${ }^{1} \mathrm{U}$ ma discussão, um debate, um conflito, batalha ou guerra sempre se realiza em dois momentos. 0 primeiro é aquele em queos contendores agem presentemente uns contra os outros, se enfrentam material mente com falas, escritos ou armas. 0 segundo é aquele em que, terminadas as hostilidades, dirimidas, superadas, eliminadas ou sufocadas as diferenças, discute-se sobreo ocorrido. $\mathrm{N}$ em sempreos agentes em liça são os mesmos nestes dois momentos e nem sempre o que está em jogo é da mesmanatureza.

Um feito bélico de grande retumbância, por exemplo, costuma dar lugar a feitos literários de sucesso. Assim foi com a perda e a retomada da Bahia em 1624 e 1625.

A cidade de Salvador era parte integrante das estratégias de grandes beligerantes na Guerra dosTrinta Anos - basicamente, para efeitos do que interessa nestetrabalho, os Países Baixosea Espanha - e, como não poderia deixar de ser, sua ocupação e retomada foi acompanhada de numerosas publicações relatando einterpretando o acontecido desde a chegada à Europa das primeiras notícias relativas ao sucesso batavo atéquase 1630. Tratava-se, por um lado, não apenas de tomar a cidade, apropriando-se das riquezas locais, mas também de anunciar a proeza ea conseqüente quebra do domínio exclusivo da M onarquia Católica no Atlântico Sul. A expulsão dos 
holandeses, por outro lado, também foi ocasião paraC astela alardear sua supe rioridade bélica emostrar a inutilidade da rebeldia das Províncias U nidas. ${ }^{2}$

0 problema quenos ocupa no presenteestáligado a estaúltima parte da guerra, à di sputa pelo acontecido que se seguiu logo após a dissi pação do fumo dos canhões em 30 de abril de 1625. Essa segunda batalha, o objeto destetrabalho, não envolveu as forças católicas contra osheréticos deH olanda; isso fora resolvido no terreno dos fatos, em Salvador. 0 conflito de que se trata neste texto opôs combatentes que estavam do mesmo lado do campo quente da guerra efoi travado na península, no coração mesmo dos domínios de $C$ astela: ele opôs portugueses a castelhanos. Suas armas foram relações, crônicas, poemas eo teatro.

0 tema já foi matéria de um estudo recente de Fernando Cristóvão que bem soube identificar as linhas mestras desta tensão. ${ }^{3} \mathrm{C}$ ontudo, o trabalho é por demais resumido e concentra o melhor de suas energias nos arquétipos narrativos, sem muita preocupação com o sentido das controvérsias na situação histórica dada. Por outro lado, um trabalho mais antigo deStuart Schwartz busca fazer uma análise mais abrangente do acontecido, analisando o feito de Salvador como expressão das tensões entre diversos grupos sociais ea coroa. ${ }^{4}$

0 assunto ganha importância, uma vez que as forças da M onarquia eram originárias, todaselas, dedomínios de FelipelV; eram tropas deC astela, deN ápoles, de Portugal. O s autores das rel ações e das crônicas eram todos súditos, ou vassalos, do mesmo monarca, contudo, foi acirrada a disputa pela vitória já obtida, ou seja, a disputa pelo papel de cada qual no grande feito. É certo que, tomada isoladamente, essa questão teria importância limitada; seria uma passagem curiosa acerca das tensões entrealiados numa guerra antiga, porém, diversos daqueles que, nos anos 20 do século XVII, se uniram para expulsar o holandês de Sal vador, nos anos 40 irão se levantar contraa M onarquia, acelerando sua decadênciana política européia. ${ }^{5}$ Talvez, coincidentemente, no momento das rebeliões, apenas o reino mais diretamente comprometido com a retomada da Bahia - Portugal - conseguiu assegurar sua independência, com isso, o problema desta guerra de tintas ganha uma projeção para muito além da curiosidade.

Afinal, haveriajá em 1625 um mal-estar significativo entre portugueses com relação ao domínio castelhano? Q ual sua extensão real? Q ual seu 
significado? Seria possível detectá-lo entre relatos ecrônicas de uma batalha vencida pela M onarquia Católica, na qual al guns destes mesmos portugueses tomaram parte? A própria apresentação destas questões já envolveproblemas rel evantes acerca da política lusitana da primeira metade do século XVII. As tentativas de solução, por outro lado, envolvem bem mais que uma constatação direta em fontes documentais.

Em 1625, a Europa vivia as primeiras décadas da É poca Barroca enão seria esperável encontrar abundantes manifestações claras edistintas de descontentamento entre religiosos, letrados efidal gos portugueses com relação a seu Rei. ${ }^{6} \mathrm{O}$ s alinhamentos políticos evidentemente existiram, as tensões entre grupos em disputa pelo poder certamente foram agudas, mas nem sempreas dissensões se manifestavam abertamente; seus modos de expressão usavam eabusavam da dissimulação, do duplo sentido, das metáforase das elipses. 0 apelo a estegênero de recurso foi abundantena diplomacia e na política do período, encontrando inclusive quem lhe desse expressão literária e filosófica: Torquato A cetto, por exemplo, escrevendo em N ápoles sob o domínio espanhol, publicou o livro D ella Dissimulazione 0 nesta, onde defendea dissimulação contra o poder tirânico como forma de sobrevivência na arena política. ${ }^{7}$

Levando em consideração essa característica, um exame da documentação deépoca disponível, principalmenteo material impresso (relações da batal ha, crônicas, teatro), poderevelar um estado deânimo entre portuguesese castel hanos que regozijo da vitória costuma abafar ou queo desprezo pelo assunto costuma esconder.

Sem pretender encontrar respostas unívocas às questões postas mais acima, trata-se aqui de identificar manifestações, ainda que dissimuladas, do mal-estar português (ou de al guns portugueses) diante dos castel hanos (mas também destes com relação àqueles) ede buscar alternativas para a sua interpretação.

Em 1623, no dia de São Tomé, o padre Bartolomeu G uerreiro, jesuíta, proferiu um sermão exaltado na Capela Real em Lisboa. 0 habilidoso inaciano associava o santo padroeiro da Í ndia às proezas lusitanas do século anterior e protestava veementemente pelo estado de abandono em que se 
encontravam as conquistas do reino. Guerreiro se serviu habilmente dos poderosos recursos da oratória fazendo o santo falar por sua boca aos seus próprios ouvintes. Disse S. Toméà corte de Lisboa:

E que viva eu hoje vendo senhoras de todos estes meus mares as bandeiras de $M$ auricio de $N$ assau herege, apostata maldito, $\&$ filho do outro, em lugar das $C$ hagas do Redemptor, $\&$ das armas dos netos del Rey $D$. $M$ anoel, meu senhor, que tanto me honrou com ellas. ${ }^{8}$

Para o jesuíta, o problema não se limitava ao assédio herético às conquistas da "verdadeira religião". A decadência em quecaíram estesdomínios do $O$ rientedevia-seà cobiça dos $V$ ice-R eis, dos capitães e dos comerciantes mais preocupados em colher riquezas que em protegêlos. 0 tema abordado por Guerreiro que mais interessa no presente éo descaso da M onarquia com os domínios de Portugal e os excessos dos ministros na tributação. ${ }^{9} 0$ abandono do reino é expresso no tema recorrente da ausência da Corte Real de Lisboa. D izo padre, apelando a S. Tomé: "N ão vos posso negar a divida ...rezam de sentimento, $\&$ dor de nam achardes em Lisboa aquelles passados R eys que vos fizeram poderoso, a vós, \& vos ricos a elles"10. 0 sermão carrega um inegável sentido de protesto. Entre relatos variados dos desacertos dos ministros castel hanos, G uerreiro lembrou ainda a "doçura" de D. J oão II para com seus vassal os e o quanto disso o monarca se valeu em seus conflitos com Castela.

0 protesto oratório deste religioso não foi feito isolado num reino melancólico eentristecido pelas agruras deum presentemenosluzido queo passado. D e fato, como assinalou J oão Francisco M arques em seus estudos sobrea parenética portuguesa do século XV II , o púlpito fora importantíssimo meio de protesto e de "agitação política" contra a degradação dePortugal sob o domínio filipino, eparticularmente contra o "abandono" das conquistasultramarinasnas décadas de $1620-40 .{ }^{11} \mathrm{E}$, neste espaço privilegiado e protegido, jesuítas, dominicanos e diversos outros religiosos exerceram sua liberdade de crítica. M arques lembra que G regório Taveira pregara em termos muito assemelhadosa Guerreiro no mesmo ano de 1623. Também Antônio de O liveira ressaltou o papel do púlpito na oposição política portuguesa durante o domínio castelhano. ${ }^{12}$ Estes protestos oratórios exprimiam vivos descontentamentos com reais perdas portuguesas no 0 riente. Em 
meados de 1622 - cerca de um ano antes do sermão do padre G uerreiro M acau havia sido assediada pelos holandeses da Companhia do 0 riente e O rmutz caíra nas mãos dosingleses ede seusaliados persas. Como sabemos, o predomínio portuguêsnaquela região do mundo vai sendo obrigado aceder espaço físico e comércio a seus concorrentes ocidentais até meados do século XVII. N o começo da década de 1620, os lusos tinham maisa chorar além do desaparecimento deseu rei. ${ }^{13}$

Segundo atesta um importante memorialista, a notícia da perda de Salvador chegou a Lisboa em jul ho de 1624 e causou grande impacto. Rapidamente, o governo de Portugal organizou coleta de fundos, recrutamento e armamento de uma frota para a retomada da cidade. Ao que diz 0 cronista, o esforço do reino contou com sólida colaboração dos três estados. A câmara de Lisboa forneceu quase a metade do arrecadado; 0 D uque de Bragança, quase um décimo; 0 arcebispo de Braga, cerca de cinco por cento. $\mathrm{No}$ que diz respeito ao engajamento, o memorialista registra do seguinte modo o empenho dos portugueses:

Aos 22 doutubro da dita era se mandou botar pregão que todo omiziado de qualquer calidade que fosse que quisesse ir narmada se viesse asentar: vierão muitos mas acodio tanta gente que se tornou a mandar que os homiziados se fossem embora para donde andavão. ${ }^{14}$

A armada portuguesa saiu de Lisboa em 22 de novembro carregando diversos dos mais graduados fidal gos de espada e de vela. 0 plano da viagem previa uma espera em C abo Verde atéa chegada da armada deC astela, trazendo o comandante-mor da operação, D. Fadrique de Toledo 0 sório. ${ }^{15}$ Entre os clérigos embarcados estavam o padre Bartolomeu Guerreiro e o padre António de Sousa, ambos da Companhia de Jesus. Este segundo jesuíta, conformenos assegura João Francisco $M$ arques, foi 0 autor da tragicomédia encenada no Colégio deSanto Antão, em Lisboa, diantede D . Felipe III e da C orte, quando de sua visitaà capital lusa em $1619 .{ }^{16}$

0 cronista também conta que as primeiras novas da batal ha de Salvador chegaram a Portugal em 23 de junho de 1625 e as informações da retomada da cidade vieram duas semanas após, em 6 de julho.

$\mathrm{N}$ os meses que se seguiram, a península comemorou o feito bélico com as formas de expressão de contentamento mais vigorosas daqueletem- 
po: festas, procissões, luminárias, missas etc. Junto com as primeiras notícias também vieram as relações de guerra, as cartas oficiais e, depois, os homens que participaram dos combates. No segundo semestre de 1625, parte desse material foi impresso e vendido pelas ruas de Lisboa, M adri, Sevilha, Cádiz. A C ortefestejou intensamente, afinal, não setratava apenas da retomada de um porto importante para a economia do Império. C onforme já foi dito, a restauração da Bahia reafirmava o enorme poderio da M onarquia, num momento em que as forças católicas retomavam terreno perdido aos protestantes nos primei ros tempos da Guerra dos Trinta Anos. Além destas comemorações, $M$ adri, a capital, contou ainda com duas peças de teatro: uma, do renomado Lope de Vega, castelhano, e outra de João António C orreia, ${ }^{17}$ português.

Contudo, o feito eo desfeito não interessavam apenas aos peninsulares. Também entre os inimigos da M onarquia C atólica a proeza foi relatada e divulgada em textos impressos, particularmente nos Países Baixos, por razõesóbvias. Talvez a relação mais conhecida entrenós seja aquela de ohann G regor Aldenburgk (soldado engajado nastropas que ocuparam Salvador), traduzida ao português havia uns quarenta anos ${ }^{18}$. Embora trate de um feito de guerra, esta relação busca aproximar o sucesso dos relatos de viajantes ao N ovo M undo definais do século XV edo início do XVII, descrevendo peixes, frutos, tubérculos e ressal tando a antropofagia dos índios e sua ação selvagem nos combates. 0 texto é muito detalhado e se revelou bastanteútil na exposição do problema queinteressa ao presente trabalho.

Entre essas relações publicadas nos Países Baixos, e com interesse adicional por se tratar de relato dirigido ao público da Inglaterra, em 1626 apareceu em Roterdam a Plaineand True Relation, de autor inglês que teria feito parte das tropas a serviço dos holandeses, ${ }^{19}$ texto curioso que denuncia os erros dos oficiais e critica seu comportamento durante a ocupação (bebiam e desfrutavam das prostitutas de Salvador). N esta publicação, o problema das tensões que opunham portugueses e castel hanos aparecelogo no início com a expressiva passagem: "T hepeoplethat arethenaturall inhabitants thereof are the Brasillians, they which are now the chiefest are the Portugals. The Spanish King clames soveraigne, though by some denyed, and by the rest unwillingly acceped of".${ }^{20} \mathrm{D}$ e certa forma, a relação reproduzia um modo de ver comum à diplomacia das monarquias rivais à Espanha havia muito. ${ }^{21}$ 
As relações do grande feito, publicadas na península, são numerosas. Encontram-se relatos brevíssimos, escritos por soldados, composições mais detal hadas e atémesmo volumes relativamente longos sobre a empreitada. Entreestesúltimos, conta-se o conhecido livro do padre Bartolomeu Guerreiro, de quem já se tratou mais acima: Jornada dos Vassalos da Coroa de Portugal. ${ }^{22}$ Ainda no prólogo, quando o livro vem sendo apresentado ejustificado, o jesuíta afirma querer contar o que "na verdade passou na Bahia pela coroa de Portugal", pois foram "sucessos muito dignos de memória". ${ }^{23}$ Essa preocupação em estabelecer a verdade é expressiva de um modo um tanto convencional de apresentar as motivações que animam os cronistas de praticamente todas as épocas, contudo, há que se levar em conta as circunstâncias em que ela se expressa. D ado o forte engajamento de G uerreiro na crítica ao abandono do U Itramar, assinalada mais acima, elembrada também sua proximidade à casa de Bragança, ${ }^{24}$ não se pode deixar de considerar que talvez a preocupação com a verdade dissimule um conflito ou uma condenação efetiva a outras relações em circulação no período, afinal, não faz muito sentido pensar em estabelecer a verdade sem que a falsidade esteja de algum modo presente.

ConformeStuart Schwartz intuiu, o próprio uso do termo "vassalo" é significativo..$^{25} \mathrm{~N}$ a realidade, essa palavra não se sobrepunha a "súdito" - que viria a substituí-la no uso corrente. "Vassalo" remete o leitor a uma faixa estreita dos "súditos", a nobreza, eainda carrega um apelo com um ligeiro tom arcaico, ao menos aos olhos do presente. É certo que essa tonalidade não teria, em 1625, o mesmo impacto que possui atualmente, mas sem dúvida ela remete o leitor à nobreza, mais que a qual quer outro segmento da sociedade. E foi disso mesmo que Guerreiro tratou na sua Jornada; lá estão indicados os esforços de inúmeras casas nobres, nomeados diversos fidalgos dealta titulação, muito mais do que qual quer outro agrupamento social. A participação de gente das cidades - mercadores, financistas, corporações - ou de religiosos regulareséreduzida na narrativa, embora as contribuições financeiras do Conselho de Lisboa tenham sido destacadase o nome de al guns grandes comerciantes também. G uerreiro parece querer mostrar que ostrês estados envidaram esforços para a empreitada, embora a jornada efetiva fosse realizada pelos fidalgos, afinal, a guerra sempre foi assunto próprio dessegrupo. 
Chama a atenção nesse texto o fato de se tratar apenas de uma crônica das forças portuguesas enviadas à Bahia para recuperar Salvador, coisa identificada até mesmo pelo título da publicação, mas a expedição, no conjunto de sua organização, buscou refletir o que de mais sólido possuía a M onarquia Católica naquele momento: tropas de Portugal, de $\mathrm{N}$ ápoles e da "Espanha" sob o comando de um dos mais renomados chefes militares da época, D. Fadrique deToledo.

U ma substantiva carga simbólica pesava sobre esse arranjo, quase que uma alegoria dos domínios da M onarquia. Pode-sedizer quesimplesmente não houvenenhuma expedição portuguesa à Bahia, apesar de ainda encontrarmos esse tipo de referência em manuais relativamente recentes. ${ }^{26} \mathrm{O}$ padre G uerreiro tinha clara essa evidênciae, ao escrever apenas sobre os portugueses, justificou-se do seguintemodo:

D e sorte que tudo o que nesta relação se vir disposto em distinção, e capítulos, he tirado com muy ex acto, e rigoroso cuidado, e juízo, de verdadeiros, e autênticos papeis das secretarias reais da Coroa de Portugal. Q ue foi a causa porque esta relação se não estendeo ao que da Coroa de Castella entrou na empreza; que ainda que foy muyto no gasto de tão grande armada, no numero de capitães, e soldados de varias naçoens, e Reynos de sua M agestade, que nella forão: no valor, e prudência do general, faltarãome as particulares noticias, e relaçoens, sem que não pode aver historia verdadeira". ${ }^{27}$

Fixar a verdade de modo claro não foi preocupação exclusiva deste jesuíta. Também o cronista de D . Felipe, TomásTamayo de Vargas, na sua história (Restauracion dela Ciudad D el Salvador, I Baia deTodos- Sanctos), encomendada pelo próprio rei, reclama o estabelecimento da verdade. Anteposto a seu texto, Tamayo apresenta uma dedicatória em que explica sua obra. 0 cronista não deixa de aproveitar o fato de haver composto sua história por força de encomenda real, reforçando sua versão dos fatos pelo acesso a documentos dos conselhos de Estado e da G uerra:

que en el sagrado de las secretarias de aquellos consejos en las coronas de Castilla i Portugal solo estan patentes, a quien escribe por orden de su Rei, i cuia fè no puede padecer nota de sospecha, aun com los mismos emulos de sus glorias. ${ }^{28}$ 
Tendo publicado seu relato mais de três anos depois dos acontecimentos, Tamayo buscou explorar o que sobre o grande feito se havia escrito anteriormente. Ele afirma ter se baseado em três relações mais detal hadas, entre elas a do padre G uerreiro, sem perder a ocasião de comentar que 0 texto do jesuíta "solamentetrata de lo quea Portugal sedebio en esta empressa, com al gumas particularidades dignas desu diligencia"..$^{29} \mathrm{As}$ particularidades dignas da diligência do jesuíta português provavelmente são os elementos da Jornada dosVassalos, e ainda de outros relatos contemporâneos, que se contrapõem àsnarrativas castel hanas, em geral, eàquela sua maior sínteseo livro de Tamayo de Vargas. A crítica dissimulada ao escrito de Guerreiro vem à tona no fechamento da dedicatória:

... no admite la historia à las singularidades qui aqui se dilatan, confiessolo; pero esta es mas relacion historial de un sucesso particular, que historia perfecta, en cuio decoro no caben tales menudencias; aqui son forçosas. $\mathrm{N}$ inguna he dexado por negligencia, o malicia. En todas han estado lexos de mi animo el odio i la afficion, siendo solo mi cuidado la verdad de las acciones de cada uno, sin distinccion de naciones. [...] esta vencedora nacion [C astela] solamente jacta por suias las que conservan en las memorias de los doctos que las aciertan, i de los nobles que las califican; lo demas es passatienpo de gente ociosa que se dissimula porque no se puede remediar. ${ }^{30}$

Parecenão ser excessi vo identificar nesta passagem uma condenação ao escrito do jesuíta português, seguida de uma séria reprimenda pela incapacidade de G uerreiro em fazer evoluir favoravelmentesua própria situação. Ele dissimularia o que não tem condições de consertar.

$\mathrm{N}$ a realidade, fixar a verdade também é preocupação de diversos outros escritos mais ou menostardios sobre a perda ea retomada de Salvador. Aquele que étalvez o mais famoso dos autores desses escritos, o padre Antônio Vieira, deixou seu testemunho na carta ânua da C ompanhia de J esus, enviadaa R oma em 1626 ecorrespondendo aos doisanos anteriores. Vieira, então jovem e promissor jesuíta, participara dos acontecimentos primeiro como vítima da invasão herege e depois como observador privilegiado. 0 religioso ea maior parte dos seus pares estiveram na aldeia do Rio VermeIho, de onde se organizara a resistência dos moradores do Brasil. ${ }^{31}$ Este jesuíta escrevera para "dizer também a certeza do que se passou na realidade, 
para que a verdade tenha lugar e se não creiam al gumas falsidades que do caso se contem". 32

Também para quem esteveem Salvador duranteos acontecimentos de 1624-25, declarar a verdade é algo que só faz sentido para se opor a uma inverdade, uma falsidade, uma mentira que, por alguma razão, incomoda. Aquilo que estava incomodando Antônio Vieira, Bartolomeu G uerreiro e Tamayo deVargas certamente não eram as mesmas coisas. Aliás, conforme espera-se ver confirmado nas páginas que seguem, o incômodo de um seria, antes detudo, o escrito do outro, a "verdade" defendida pelo outro.

Essas "verdades", quetanto incomodaram os mais importantes autores das crônicas, encontram-se principalmente nas descrições de momentos particulares do acontecido. U m exame detido de uma amostra suficientemente grande dos textos evidencia que desde as motivações dos invasores atéa retirada da armada da cidade já recuperada, o desacordo quanto a alguns temas ébastantegrande. D iante da pouca utilidadee da inconveniência de uma exposição exaustiva desses contrastes, será mais adequado restringir a análise a temas de maior poder de síntese, como o são a perda da cidade ea avaliação da ausência de resistência ao ataque holandês; a reunião e a viagem da armada atéa Bahia; efinal mentea rendição dosinvasores ea entrada na cidade das forças católicas. Ao examinar as diversas exposições desses elementos das narrativas, tem papel decisivo o tratamento dado aos circunstantes: portugueses da armada, portugueses da Bahia (ou luso-brasileiros), castelhanos, índios e negros ecristãos-novos.

Pelo que contam todas as relações da guerra, a tomada de Salvador pelos holandeses foi operação fácil: a cidade foi ocupada pelos invasores sem maiores resistências. Porém, se há sólida concordância quanto a isto, existegrande diversidadequanto a outros elementos, francamente secundários, que evidenciam condenações mai ores ou menores ao governo do Brasil, exercido sempre por gente portuguesa, conforme um item importante das cortes de Tomar. ${ }^{33}$ Por exemplo, é comum entre os autores apontar a covardia dos portugueses da Bahia, queteriam entregue a cidade sem combate, desamparando aquilo quetinham a responsabilidadededefender, aban- 
donando pertencese riquezas, fugindo aceleradamente tão logo a iminência do assalto ficaram patente.

$M$ as se a referência à imprevidência e incompetência do governador $D$ iogo de $M$ endonça Furtado éassinalada pelo padre G uerreiro, por exemplo, lembrando também do medo que tomou conta dos moradores de Sal vador, entre autores castel hanoso problema da tomada da cidade ganha outras proporções. Para estes, os temas passam muito além da incapacidade, eles são covardia e traição.

A idéia de que moradores da Bahia acolheriam a invasão com bons olhos foi argumento aventado pouco antes da investida, num escrito de propaganda daC ompanhia H olandesa, o livreto deJ an Andries M oerbeeck, M otivos porque a Companhia das Índias 0 cidentais devetentar tirar ao Re deEspanha a terra do Brasil. ${ }^{34}$ Este texto foi lido na Península e referido por diversos cronistas da batalha de Salvador, tanto por escritores de Castela quanto por portugueses, embora os jesuítas $V$ ieira e G uerreiro não o mencionem. Eugenio de $N$ arbona y Zuñinga, por exemplo, refere-se explicitamente a um concerto de gente da cidade com os invasores:

... al amanecer entrò el enemigo sin resistencia, avisado, y llamado (según se dixo) de uno de los vecinos, que se acomodaron con la fortuna del vencedor; entraron en fin, y no hallando en la ciudad sino algunos negros, y portugueses, hebreos de nación, apostatas del Evangelio, que esperaban el suceso, y havian parte en el trato, con otros que de su nación fugitivos esperaban en O landa... ${ }^{35}$

Q uando setrata de traição, evoca-se com freqüência aqueles a quem o cristianismo já personificou, em diversos momentos, à própria traição: judeus, hebreus ecristãos-novos. A referência a essegrupo dentreos moradores deSal vador ébastante valorizada por escritores de C astela, embora não tanto entre os portugueses, sobretudo pelos cronistas da Companhia de Jesus.

0 padre Guerreiro, sugerindo que uma hipotética traição de portugueses do Brasil não era necessária para facil litar a invasão, assinala que havia entre os inimigos ao menos dois holandeses que já estiveram presos no Brasil anos antes: um que fora aprisionado no Rio e fugiu da cadeia e 0 outro, "estando preso e condenado à morte, se sobresteve na execução por 
ordem de Sua M agestade, em tempo do governador D. Luís de Sousa" ${ }^{\prime \prime}$. $\mathrm{O}$ u seja, havia quem conhecesse bem o lugar nas naus de $\mathrm{H}$ olanda.

Porém, a valorização do papel dos cristãos-novos pelos cronistas de Espanha e seu desprezo por parte dos escritores portugueses fica melhor exemplificada pela comparação entre as duas conhecidas peças de teatro compostas sobre o feito. Felix Lope de Vega, na sua comédia El Brasil Restituido, atribui imenso papel à suposta entrega de informações e colaboração dos cristão-novos de Salvador com os holandeses. A peça tem início com um diálogo entreD . G uiomar, cristã-nova, eD . D iego, fidal go português. A passagem écuriosa, pois $D$ iego estáabandonando sua amantegrávida (sem o saber) por conta de sua origem. A trama se desenvolve com referências explícitas à colaboração dos pais de G uiomar e seus próximos com os invasores. Esse personagem acaba por se casar com Leonardo, militar holandês intermediário na traição, que não sabia do estado de sua "noiva", e termina entregue a M achado, o gracioso ${ }^{37}$. Por outro lado, João António Correia, natural de Lisboa, na sua comédia La Perdida y Restauracion de la Bahia de Todos los Santos, sequer fala de cristãos-novos. I sso nem mesmo teve a honra de uma rápida menção.

Por outro lado, se existeum referente comum no quetoca ao interesse holandês na ocupação de Salvador - tomar postos comerciais - , o peso desseargumento apresenta-se um tanto esmaecido no cronista deD . Felipe. D e fato, Tamayo deVargas éhomem que vê os acontecimentos a partir da cortede M adri: ele não poderia deixar de iniciar sua história considerando 0 andamento dos conflitos entre os Estados europeus. Por este tempo, as forças católicas se encontravam em forte retomada territorial diante da aliança protestante no Leste do Velho M undo. 0 registro da iniciativa da Companhia $\mathrm{H}$ olandesa das I ndias $\mathrm{O}$ cidentais vem fortemente associado à evolução da guerra na Europa, contudo, os demais autores de relações da batal ha de Sal vador costumam circunscrever a ação holandesa aos marcos do interesse comercial, boa parte deles usando como referência o folheto de M oerbeeck.

A discrepância entre as narrativas castel hanas e textos de portugueses também é significativa no que toca ao segundo problema assinalado mais acima: a partida das armadas em socorro à Bahia. Bartolomeu G uerreiro, o jesuíta português, indica que Felipe IV teria enviado comunicados aos go- 
vernadores de Portugal pedindo para ultimar os preparativos da expedição até final de agosto de 1624; o monarca teria ainda avisado que a armada sairia de Lisboa. M aistarde, em 27 de outubro, eleteria mandado a armada portuguesa reunir-se às demais em Cádiz. Por fim teria ordenado que a esquadra lusa deveria aguardar em C abo Verde pela chegada dos navios de C astela. Todas as relações que tocaram no assunto são concordes em assegurar que os portugueses levantaram âncora de Lisboa em finais de novembro de 1624 eque os castelhanos, deCádiz, em 14 dejaneiro de 1625. N enhuma das crônicas examinadas deixa de assinalar que os vassal os portugueses aguardaram por mais de quarenta dias a chegada da Almirantee dos demais componentes da expedição.

$M$ anuel de Faria e Sousa, humanista e historiador do reino de Portugal, trata do problema no seu livro publicado em 1628, Epítome de las $\mathrm{H}$ istorias Portuguesas. É importantereter que o autor esteve entre os entusiastas da U nião I bérica, defendendo neste seu tratado o domínio filipino eos valores da nobreza lusitana mais tradicional, sempre responsabilizando 0 envolvimento comercial dos fidal gos pela decadência em que o reino caíra desde D. M anuel, o Venturoso ${ }^{38}$. Faria eSousa expõeo episódio da partida e reunião das armadas do seguinte modo:

A um mismo tiempo se empezaron a aprestar, mas com desigual diligencia se aprestaron; la portuguesa aguardo um mês em el puerto de Lisboa por la Castellana, y saliendo em noviembre sin ella, aguardola em la islã de Santiago (principal de lãs de Cabo Verde) hasta el mês de febrero, em que se vieron juntas: tardança considerable, y que se hizo provechosa al enemigo: no fue sin causa la desigualdad porque el um apresto se hizo com amor, y com hazienda de vassallos, y el outro com hazienda D el Rey, y com tibieza de ministros. ${ }^{39}$

Para al guns escritores castelhanos, o retardo da armada real compensou-se numa mal dissimulada crítica à navegação da frota que partira de Lisboa. Juan deValencia y G uzmán, por exemplo, trata do seguinte modo o naufrágio de uma embarcação portuguesa:

uma dellas [embarcações] se le perdio el galeon la conçepcion em que hiba embarcado el maestro de campo Antônio M uñiz Bareto ahogaronse çiento y quarenta hombres (...) salbose la Artilleria y perdiose todo ho demas en que abia muchas cosas de balor... ${ }^{40}$ 
Reunidas as armadas, tomou-se o rumo do Brasil. A viagem, quenunca era tranqüila naqueles tempos, também se transformou em cenário de conflito entre as narrativas. D. Tamayo de Vargas não deixa de assinalar a pouca destreza dos portugueses na navegação em alto mar: repetem-se as ponderações de quea armada reunida avançava com gal hardia "aunquelos baxeles de Portugal parecian menos veleros por darse siempreatras", ou de que o comando castelhano procurava "no perder la Armada de Portugal, que seguia con difficuldad la deC astilla". Associado a isso, não faltam considerações sobre a fidel idade lusitana, sobretudo no que diz respeito ao reconhecimento do comando eda superioridadecastelhana. Valenciay Guzmán descreve do seguinte modo a reunião em C abo-Verdeda armada do Brasil, depois de registrar o desacerto da frota portuguesa:

... el regocijo y contento que huvo generalmente fue superior y estraordinario fue nuestra armada siguiendo su capitana general y entrando con el orden y concierto que se acostumbra abatieron la capitania y almiranta de Portugal sus estandartes en conocimiento de imferiores... ${ }^{41}$

C uriosamente, na maior parte das crônicas, os feitos dos luso-brasileiros entre a invasão e a chegada dos so corros quando são apresentados o são antes como vilezas do que como atos de guerra, ou de bravura. Uma proeza sem dúvida significativa, a morte do comandante inimigo, coisa que semprefoi considerada importante nas batal has, é apresentada como feito desfavorável, por quase todos os escritores, expressivo mais da indignidade que das virtudes dos combatentes. A queda de Van D ort, o general holandês, por exemplo, é referida como evento sanguinário, injustificado equase bárbaro por N arbona y Zuñiga:

... con gran presteza el Portugues le puso el pie sobre el pecho haviendole herido de una cuchillada y aunque el coronel le pediò que no le matasse diciendo que era el $G$ eneral no quiso perdonarle la vida, matole al fin y quitole la espada, y cortole un dedo en que se trahia una sortija para que fuesen testigos de la victoria, y los demas soldados triumpharon della, aunque sangrientamente, porque demas de despoxalle le cortaron partes de su cuerpo, cosa que los $\mathrm{H}$ olandeses tuvieron por denuestro afrentoso, y se quexaron dello con razon.... ${ }^{42}$ 
Vieira, que descreve os acontecimentos a partir do Rio Vermelho, e que não cansa dedar relevo à ação de seus pares e dos indígenas que com eles combatiam, trata da morte de Van D ort em termos muito diferentes, afinal, nas condições em que se encontravam os portugueses da Bahia, não havia muito lugar para rituais de guerra e para privilégios de comandantes. Diz estejesuíta:

Repartidos os capitães e soldados pela dita ordem, o primeiro encontro, em que deram a conhecer sua apostada determinação ao inimigo, foi que, vindo do porto de S. Filipe, vizinho a N ossa Senhora do M onserrate, o seu coronel ou governador, homem intrépido e afamado em uma e outra guerra, naval e campal, assim em Flandres como nas armadas, acompanhado de cem soldados de guarda, rebentaram os nossos de uma emboscada contra eles, e um remeteu com o governador, que vinha a cavalo, e 0 derrubou. Tanto que este caiu, caiu com ele 0 ânimo aos pés dos soldados que o acompanhavam, como bem se viu no efeito, porque, faltando-Ihe às mãos para resistirem, só nos pés Ihe sobejou para fugirem. ${ }^{43}$

0 comandantegeral das forças portuguesas, D. M anuel de M enezes, em sua relação que não foi publicada, também se refere à morte do chefe inimigo. Para o comandante das forças portuguesas, o episódio ganhou 0 seguinteteor:

Sayo a 15 de junho o coronel João D oart a cavallo acompanhado de alguns soldados tocando trombetinha diante; acudio este capitão [Francisco de Padilha] com a gente de sua bandeira, e do primeiro arcabusaço matou o cavallo do coronel, earremetendo sem escutar rasões, ou promesas Ihe cortou a cabeça, e invistindo a companhia os poz em fugida, e lhes foy no alcance hum gran pedaço. ${ }^{44}$

$\mathrm{N}$ a verdade, o juízo sobre o fato dos luso-brasileiros terem matado 0 comandante holandês é bom indicador dos valores dos envolvidos e do problema que se busca caracterizar desde 0 início deste texto. G uzmán, Tamayo, M enezes demonstraram, em graus diversos, espanto com a brutalidade do acontecimento, afinal tratava-se deum fidal go ecomandante das forças inimigas enão seria digno de sua condição matá-lo daquela maneira. Além disso, a forma com que os luso-brasileiros agiram colaborou com a 
idéia de vileza atribuída a eles desde a exposição da perda da cidade para as forças inimigas. Por outro lado, seria perfeitamente esperável que Vieira expusesse o feito de outro modo, desalojado que foi do Colégio da Bahia, empurrado para a aldeia do R io Vermel ho etestemunha do estado em que ficaram os soteropolitanos e os do Brasil durante a invasão holandesa. Este jesuíta também dá destaqueao empenho dosluso-brasileiros dePernambuco e do R io de Janeiro em enviar reforçose comandantes militares para organizar e fortalecer a resistência, que acabou por se mostrar bastante eficaz.

$M$ as o fato de osinvasoresterem perdido seu comandante foi assinalado de modo muito diferente pelos que estavam ocupando a cidade. 0 anônimo autor daPlaineand True Relation, citada acima, trata da morte de Van D ort como algo queteve impacto decisivo no rumo dos acontecimentos. Ele identificara no desregramento dos oficiais a gran de causa da perda, e a morte do comandante das operações não poderia ser tomada como fato menor, no que respeita a evolução da combatividade dos holandeses. Ele expôs o episódio nos seguintes termos:

The same morning the Colonell with some twelve horsemen went out of the Towne, with some twenty negars and a squadron of men, the C olonell riding before some twenty yeards in a narrow path, and woods on both sides, the portugals lying in ambush got about Colonell, a negar shot him in the brest, and the portugals puld him of his horse, who kild him and cut of his head and other parts, the most of the horsemen $\&$ souldiers retired to the towne, yet an english-man brought in his head, upon which there was a great alarme, but but nothing wort the writing. ${ }^{45}$

Aldenburgk fala em diversas passagens do medo que atingiu os ocupantes da cidade tão logo ficou claro que as expectativas alimentadas por M oerbeeck não correspondiam aosfatos. Para este autor, a associação entre os portugueses da Bahia e os índios era coisa constante que influenciou decisivamente no desgaste das forças ocupantes. 0 general Van D ort, por exemplo, foi "surpreendido pelosíndios selvagens, portugueses e pretos, e ferido, bem como seu cavalo, de muitas flechas ervadas" ${ }^{46}$, antes de ter sua cabeça cortada barbaramente.

Para estemilitar, os invasores estavam literalmente cercados, sofrendo com a falta de víveres, impossibilitados de tratar com os sitiantes etemero- 
sos de suas pouco gal antes formas de combate. Justificando com a barbaridadedosinimigos seus atos deguerra bem pouco aristocráticos, Aldenburgk sintetiza esta situação na seguinte passagem:

U ma vez que não se podia esperar clemência dos portugueses, brasilienses, ou negros, pegamos do resto considerável de prisioneiros que possuíamos, levamo-los para fora da cidade, colocamo-los amarrados uns aos outros, próximo à porta do capitão I senach (S. Bento), junto ao convento, e ali os arcabuzamos. ${ }^{47}$

Aliás, a "indignidade" dos combatentes da terra, daqueles luso-brasileiros que resistiram a partir do Rio Vermelho, também é ressaltada em outro momento importante dos acontecimentos. Rendidos os holandeses, ocupada a cidade pelas forças católicas, reportam diversos cronistas que os portugueses desejavam reunir osprisioneiros em suasembarcaçõeseincendiálas. A idéia não foi acolhida por $D$. Fadrique, mas a sua presença nas narrativas castel hanas enas crônicas dos invasores ressalta aos ol hos dos leitoreso barbarismo português, já apresentado na proximidade entre os lusos e os indígenas.

As tensões indicadas até o momento entre as variadas interpretações do feito de Salvador ganham contornos bem mais nítidos quando as crônicas erelações referem-se aos momentosfinais da empreitada. Para os cronistas de $C$ astela, os rituais dos vencedores coroam as sugestões indicadas ao longo dos textos: os louros da vitória caberiam aos castel hanos vencedores. O s escritores de Portugal acusaram o golpe e, em seus textos, demonstraram claro descontentamento com relação ao rumo impresso aos acontecimentos, pelos castelhanos da armada e pel os escritores de C astela.

0 cronista-mor, D. Tamayo de Vargas, refere-se à entrada católica na cidade com muita naturalidade, como se o fato de entrarem primeiro apenas soldados castel hanos fosse algo associado às funções exercidas por eles. Entraram aquel es que poderiam assegurar a segurança do lugar e controlar os bens da fazenda real associados à retomada de Salvador. ${ }^{48}$ Se houve algum saque, eD. Tamayo o reconhece, foi apenas o resultado de uma perda de controle passageira elogo punida exemplarmente: 
Algunos offiales i soldados de los reales, a quien la codicia avia sacado de sus puestos, tomando occasion de los grandes aguazeros que sobrevenian, se aprovecharon de las casas que desamparaban los que se retiraban, tan sin orden, que aunque el maestro de campo general corria la ciudad para su remedio, quedo poca gente con las banderas, cebandose los mas en el saco de al gunas casas, en particular en las que entendieron que avia mercancias... remediose con la venida presta del general, que mando que pena de la vida todos los soldados se retirassen a sus bandieras... ${ }^{49}$

Embora a condição decronista de D. Felipe colocasse D . Tamayo em posição de autoridade sobre a matéria, a expectativa entre os soldados de saquear a cidade se apresentava desde o desembarque na Bahia. Conforme um depoimento de soldado português, publicado apenas uma semana após a chegada em Lisboa das notícias da retomada de Salvador, os homens da armada sabiam que os holandeses não haviam despachado as riquezas obtidas na invasão; eisso os excitava: " $\&$ assi dizem que tem aqui tudo, do que não folgarão pouco os soldados pera dia do saco"50. M esmo que fosse intenção do comando militar castelhano evitar os excessos da tropa sobre os benslocais, os relatos coincidem sobre o fato decidade ter sido efetivamente saqueada. M as os cronistas de C astela parecem evitar chamar a atenção sobre isso, eosde Portugal parecem andar na direção oposta.

0 padre G uerreiro, narrando a entrada das forças católicas em Salvador, demonstra um profundo mal-estar com o fato de a cidade ter sido ocupada em primeiro lugar exclusivamente por fidalgos de C astela, sem a participação de oficiais portugueses, ${ }^{51}$ afinal, a precedência neste gênero de coisa, para essa gente, não era al go do que se podia abrir mão com facilidade. O smotivos de queixa não se encontram apenas nestetema; aos olhos de Guerreiro, o problema se estende aos afazeres dos soldados católicos na cidadeluso-brasileira devolvida pelos invasoresàs forças de D. Felipe, rei de Portugal:

$\mathrm{N}$ ão fique por dizer neste lugar, pois he tanto seu quem no trabalho, $\&$ perigo do cerco da Bahya, $\&$ nos mais perigos tiverão os portugueses a vanguarda, \& a retaguarda, \& guarda das portas na entrada da cidade. $\mathrm{E}$ se esta confiança dos capitães da coroa de $C$ astela, foy fundada em desejo de proveito, rezão era que se alcançasse este, a quem tanto alcançou 0 trabalho. M as o certo foi que a milícia portuguesa, se não deu por acha- 
da de outros interesses, mais que a serviço de sua $M$ ajestade, honra e reputação da Coroa de Portugal. ${ }^{52}$

Tendo recuperado a cidade aos domínios do rei, os heróis do feito não deixaram detratar Salvador como posto de saque, como sítio inimigo. A queixa de Guerreiro, neste particular, não prezou o fato de se tratar da "cabeça" dos domínios da coroa de Portugal no N ovo M undo. N em mesmo chamou a atenção do jesuíta as evidências de que os soldados saquearam os pertences dos luso-brasileiros que já haviam sido pegos pelos "heréticos". 0 problema quelheinteressava se restringia exclusivamenteà tensão peninsular: "os despojos que vieram a dois portugueses, foi a um, um quadro de $\mathrm{N}$ ossa Senhora, a outro uma sela holandesa, em contraste com abundantes despojos atribuídos aos espanhóis"53. 0 quadro da V irgem certamentenão fora trazido de Amsterdam, terra de calvinistas...

D. M anuel de $M$ enezes, preocupado que estava com o rebaixamento dos fidal gos portugueses, apresenta a retomada da cidade com conotações bastante próprias. Também para ele, o saque (ou o re-saque) da cidade não representava em si mesmo nenhum problema; a questão estava no lugar reservado aos portugueses na aventura, "se assertava hum soldado portuguez tomar hum ferro velho, ou outra coisa vil logo Iheera arrebatada, eas vezes com soberba"54. D . M anuel sintetiza suas queixas quanto ao lugar dos soldados lusitanos no simbolismo da bandeira alçada na cidade depois de arriado o estandarteholandês:

Q uinta feira primeiro de maio as dez da manhã tirada a bandeira de M aurício se plantou em seu lugar sobre a see a das armas reais de $S$. M . com castellos e leões. M atéria de notáveis descontentamentos entre os portuguezes, chamando aquillo, se foi enavertencia, odio nos castelhanos a nação portugueza que em tudo se mostrava, e nunca em tão pública aparência. ${ }^{55}$

Ainda queD . Fadrique, comandante geral das operações, tivesseremediado o mal-estar português ao levantar outra bandeira ao lado da real de Castela, D. M anuel não se satisfez. D isse ele em sua crônica, com um indisfarçável descontentamento:

A queixa das armas acudia em parte $D$. Fadrique mandando pintar huma bandeira ordinaria as armas de Portugal no lugar acostumado, e não 
havia satisfazer aos mal contentes; porque passado o primeiro impeto sendo admetidas algumas companhias italianas e portuguezas tomando toda a queixa a sua conta, como soem acontecer nos iguais de fortuna inferior, diziam que bem viam qual era a intenção de enriquecer a huns, impedir o proveito aos outros pois já naquele dia não avia cousa de sustancia, ou se alguma measse, tão escondida, que os da vanguardia na pilhage curiosos no revolver o não achariam. ${ }^{56}$

Antônio V ieira, parecendo não reconhecer osproblemas indicadospor seu confrade ou mesmo aqueles explicitados pelo comandante da armada de Portugal, apresenta do seguinte modo a entrada das forças católicas em Salvador: "D eterminadas as coisas nesta forma, dia deS. FilipeeSant'Ilago, que foi o primeiro de maio de 1625, entraram os nossos a tomar posse da cidade, e, abatida a bandeira holandesa, se arvorou a de Portugal eC astela". ${ }^{57}$

$\mathrm{M}$ anuel deFaria eSousa, o historiador do reino de Portugal, referiu-se ao saque da cidade em termos mais alarmados que os cronistas anteriores. Para ele: "hallose dentro um despojo grande, sobre el qual huvo soldados españoles que parecieron olandeses: la ciudad em ser saqueada no hallo outra diferencia sno que lo fue de aquellos, y no destos". ${ }^{58}$

Por outro lado, os homens que participaram dos acontecimentos no interior das linhas holandesas pouco se importaram com bandeiras sobrea Sé ou com a nação dos primeiros a entrar na cidade recuperada, contudo, eles registraram de modo particularmenteinteressante a entrada das forças católicas na cidade e o problema da pilhagem castelhana sobre os bens locais. Tanto Aldenburgk quanto o autor anônimo da relação inglesa registraram, em termos bastante semelhantes, a revenda aosmoradores de Salvador de suas próprias casas recuperadas pelas forças católicas. M ais que isso, eles registram o saque da cidade:

But let mee note one thing here which is worth the observation, concerning the Portugals. The prince D on Frederico a little before his goeing away sold to the portugals their houses, which before were their owne, and at his goeing away did not onely take away all goods till it came to old stooles and dores, but also stript then naked of all armes and munition, and did take away all their ordnance that was planted to sea or land-ward. So that the towne in now more weake then it was when the hollander tooke it in. M ore may be said of this but I will not. ${ }^{59}$ 
A considerar o que afirmaram estes dois soldados deH olanda, a vitória da expedição católica contra os heréticos foi também uma vitória sobre os portugueses! Principalmente sobre os portugueses do Brasil!

Conforme ficou exposto no início deste trabalho, ao disputar pela verdade, os cronistas disputavam bem mais do quea espessura de uma fatia do mercado delivros. Tratou-se da supremacia de uma versão. 0 objeto da "guerra detintas" que seguiu o feito bélico deSalvador foi o lugar da nobre za e da fidal guia de Portugal nos domínios da coroa, ocupada por cabeça castelhana; eisso era problema de primeira grandeza.

Seria certamente ingenuidade crer que, de algum modo, os escritores envolvidos anteciparam, nas letras, os sentimentos e interesses que moveram os atos perpetrados em primeiro de dezembro de 1640: a retomada da independência. A guerra detintas não expressava um sentimento nacional adormecido ou esmagado; ao contrário, expressou um mal-estar de fidalgos, e tão somente dos membros da nobreza latu sensu. 0 objeto desse desconforto, conforme foi exposto mais acima, era o lugar ocupado pelos vassal os portugueses no exercício de seu "natural" eantigo papel na sociedade portuguesa: governar, defender o reino esuas conquistas. A significativa ausência de conteúdo "autonomista" pode ser ainda intuída do fato de que um dos registros mais significativos desse desacerto saiu da pena de escritor famoso e entusiasta do domínio filipino: $M$ anuel de Faria e Sousa. Ainda mais, ao quesepôdeconstatar, o incômodo também foi recíproco: oshidalgos da armada não estiveram satisfeitos com seus pares lusitanos.

A pósa Restauração, a batal ha deSalvador perdeu importância ea guerra detinta quelhe estava associada simplesmente acabou. 0 que não impediu uma manifestação, um tanto tardia, mas bastantecuriosa de D iogo G omes Carneiro, "brasilienseenatural do Rio de Janeiro", interessado em conclamar a nobreza de Portugal à causa da independência. Esteautor refere-seà bravura lusitana em defesa das conquistas do reino ainda sob o domínio castel hano, citando o feito da Bahia como exemplo significativo. D iz ele:

... quando na Bahia do Salvador metropoli do estado do Brazil, resistirâo ao $\mathrm{H}$ olandes os portugueses, moradores, \& filhos daquella dilatada 
provincia, aonde com fineza ha tantos annos observão as leis da nova guerra que ensinarão ao mundo, em que reduzirão a temeridade a obrigações do valor. ${ }^{60}$

Por fim, cabe considerar que a tensão entre os escritores do feito de Salvador certamente não poderia passar notada apenas pelos seus próprios autores. Seria muito estranho supor que uma disputa dessa envergadura, envolvendo escritores ilustres de dois reinos governados pela mesma coroa, não fosse percebida. Pelo quefoi exposto mais acima, pode-se imaginar que a "guerra de tintas" não apresentava aos ol hos de seus leitores o caráter de uma disputa literária strictu sensu, estava diretamenteem jogo a proeminência da fidal guia de Portugal. N ão é difícil supor que uma controvérsia envolvendo o valor eas capacidades dos vassaloslusitanos de D. Felipe IV apresentava um potencial desagregador no que toca às pretensões unificadoras das armas ibéricas: se, no episódio deSalvador, boa parte dos cronistas expressaram um desacerto entre castel hanos e portugueses, o que não aconteceria numa ação conjunta das armas em qualquer outro ponto do dilatado I mpério, ou mesmo na Catalunha? 0 risco de arrefecimento dos ânimos da fidal guia portuguesa no exercício de suas funções tradicionais a serviço de seu rei poderia ser elevado. ${ }^{61}$

Ao que assegura o estudo de Stuart Shwartz, já citado al gumas vezes no presentetrabalho, o governo da M onarquia Católica percebeu o problema. D iante do andamento da guerra detintas, o Consel ho de Estado deD . FelipeIV não se furtou a tomar medidas voltadas à contenção dos ânimos: a multiplicação de relações, crônicas e histórias do feito de Salvador foi proibida. ${ }^{62}$

Conformejáfoi lembrado no início do presente texto, o fato dePortugal se rebelar cerca dequinzeanosapós a batal ha de Salvador permitepensar que osproblemas descritos são reveladores de um quadro político queacabou por evoluir num sentido inesperado. M asnão deixa de ser expressivo de uma dinâmica dafidalguia nem sempre reconhecida evalorizada. 


\section{Notas}

${ }^{1}$ O sautores agradecem ao apoio fornecido pelo CN Pq à realização destetrabalho.

${ }^{2}$ Pela quantidade de publicações já repertoriadas, em diversas ocasiões, é fácil verificar a extensão do problema. J oséH onório Rodrigues, no seu livro Bibliografia do D omínio H olandês no Brasil, Rio de Janeiro: IN L, 1949, p. 190-209, arrola mais de quarenta títulos de relações ede crônicas sobrea batal ha deSalvador. É curioso lembrar queo metódico pesquisador tenha deixado de lado exatamente o texto do mais conhecido escritor dalíngua portuguesa do século XVII, o PadreAntônio Vieira.

${ }^{3}$ CRIST Ó VÃO , Fernando. "A luta de libertação da Bahia em 1625 e a batal ha dos seus textosnarrativos eépicos". Q uinto Império, Salvador, v. 1, n. 16, 2002, p. 79-103. 0 trabalho buscaintegrar, com sucesso, contribuições extrapeninsulares à análise. Sua caracterização do conflito detextos contribuiu de forma singular para o presente estudo.

${ }^{4}$ SC H WART Z, Stuart B. "T heV oyage of the vassals: royal power, nobles obligations and merchant capital before the portuguese restoration of independence 1624-1640". The American H istorical Review, 96, 3, 1991, p. 735-62.

${ }^{5}$ A Catalunha rebelou-se em junho de 1640 , seis meses antes do levante português de primeiro de dezembro. N ápoles revoltou-seem julho de 1647.

${ }^{6}$ As mais variadas manifestações escritas de descontentamento com relação ao domínio castel hano ficaram conhecidas com o curioso nome de "Literatura Autonomista". Alguns estudos já antigos buscaram dar conta deste material, sendo o mais notável deles a obra CID AD E, H ernâni. A Literatura Autonomista sob osF elipes. Lisboa: Sá da C osta, sd.

${ }^{7} 0$ texto de Acetto conheceu tradução brasileira recente pela editora $M$ artins Fontes. 0 estudo mais importante sobre este tema é o trabalho VILLARI, Rosario, Elogio della D issimulazione, la lotta politica nel seicento. Bari: Laterza, 1987.

${ }^{8}$ GUERREIRO, Bartolomeu. Sermão quefez o PadreB ertolameu Guerreiro da Companhia de Jesus, na cidade de Li isboa na Capella Real, dia deSãoT home, anno de 1623, cuja festa como de Padroeiro da India celebra, por ordem dos ReysoTribunal daquelleEstado com offertaspublicasdas drogas delle. Lisboa: Pedro C raesbeeck, impressor del Rey, 1624, p. 7r. A última frase deste trecho citado não é destituída de significado político. H á uma ambigüidade expressa na referência aos descendentes deD . M anuel. Entreseus "netos" haviacertamenteFelipell, mas também aqueles outros pretendentes à coroa de Portugal que perderam a disputa em 1580, entreelesD . C atarina de Bragança, avó deD. J oão, o monarca da Restauração do reino.

9 “M as nestefavor com queos menorestem obrigação de acodir ànecessidade do Rey, há de entrar afidelidade dos ministros: a não tomarem mais dosvassalos, que pedea necessidadedo Rey". GUERREIRO, 0 p. Cit. p. 10v.

${ }^{10}$ Idem, p. 8v.

${ }^{11}$ M ARQ U ES, João Francisco. A Parenética Portuguesa ea D ominação Filipina. Porto: IN IC, 1986. 
${ }^{12}$ O LIVEIRA, António de. Poder eoposi ção política em Portugal no período Filipino (15801640). Lisboa: D ifel, 1991;

. M ovimentosSociaisePoder em Portugal no séculoXVII. Coimbra: IH ES/FL, 2002.

${ }^{13} \mathrm{Cf}$ a esse respeito, o texto clássico $\mathrm{BO} O \mathrm{XER}, \mathrm{C}$ harles R. 0 Império $\mathrm{M}$ arítimo Português. São Paulo: Companhia das Letras, 2002, especialmentep. 120-163.

${ }^{14}$ SO ARES, Pero Roiz. M emorial. Coimbra: Universidade deC oimbra, 1953, p. 466.

${ }^{15}$ Idem, p. 465-75.

${ }^{16} \mathrm{~N}$ ote-se que a peça do padre Antônio deSousa, encenada nesta ocasião, versava sobre as conquistas de Portugal no 0 rientee exaltava $D$. M anuel I e os gran des portugueses do século XVI ligadosa estaproeza. Cf. M IM O SO, João SardinhaSJ. Relacion dela Real Tragicomédia com quelospadresdela Compañia deJ esusem su Colégio deS. Anton de Lisboa recibieron a la M agetad Católica deFelipell dePortugal. Lisboa: JorgeRodriguez, 1620.

${ }^{17}$ LISBO A, J. C arlos. U ma peça desconhecida sobreosholandesesna Bahia. Rio deJ aneiro: IN L, 1961. A peça foi editadano século XVII, no volume: ComediasN ovaseEscogidas, vol. XXXIII. M adri, 1670, p. 201-33. El Brasil Restituido de Lope de Vega foi editada diversas vezes em coletâneas do teatro espanhol. A licença deencenação foi emitida em 29 de outubro de 1625, conformepodeser visto no estudo BARREIRO, JoséM aria V iqueira. El lusitani smo deL ope deVega y su Comedia "El Brasil Restituido". Coimbra: FLU C/C oimbraEditora, 1950, p. 217-8.

${ }^{18}$ ALD EN BU RG K, J ohann Gregor. Relação da Conquista eperda da cidadedo Salvador pelos hol andesesem 1624-5. São Paulo: Revista dosTribunais, 1961.

${ }^{19} \mathrm{~A}$ plaineand truerdation of thegoing forth of a $\mathrm{H}$ olland flectetheeleventh of november 1623 , to thecoast of Brasil with thetaking of Salvador, and thechief occurrencesfalling out there, in thetime of thehollanderscontinuancetherein. Asalso thecoming of the sapnhish armado to Salvadoe, with thebeleaguering of it, theaccedintsfalling in thetownethetime of beleaguering... Roterdam, 1626.

${ }^{20} \mathrm{~A}$ plaineand truerelation, cit. p. 3.

${ }^{21}$ Poucosanos antes dos acontecimentos deSalvador, um impresso circulou em Paris dando novas da passagem deFelipellI por Lisboa, do juramento das cortes a seu sucessor eda atitude dissimulada dos lusitanos com relação aos seus verdadei ros sentimentos para com o seu rei castelhano. Cf. Leserment defidelitéfaict au princed'E spagne, à l'ouverturedesE statsdu Royaume dePortugal. Paris: N icolas Alexandre, 1619, p. 7.

${ }^{22}$ GU ERREIRO, Bartolomeu SJ. Jornada dosvassalosda coroa de Portugal, pera serecuperar a Cidade do Salvador, na Bahia detodos os Santos, tomada pollos 0 landezes, a oito de mayo de 1624 , \& recuperada ao priméro demayo de 1625 . Feita pollo padreBertolameu Guerreiro da Companhia deJ esus. Lisboa: M attheusPinheiro, 1625. 0 jesuíta, queesteve embarcado na frota portuguesa, tinha seu volumepronto em outubro dessemesmo ano, conforme atestam as primeiras licenças para publicação, datadas de 7 de novembro.

${ }^{23}$ I dem, páginas não numeradas.

${ }^{24} \mathrm{G}$ uerreiro viveu sete anos na cortedos $\mathrm{D}$ uques de Bragança, foi confessor de D. T heodósio epregou nas exéquias celebradas em 1630 em suamemória. 0 sermão foi publicado doisanos 
depois: ff. GUERREI RO , Bartolomeu. Sermam quefez o R. P. Bertolameu Guerrerro da Companhia de Jesusnas exequias do anno que sefizerão ao sereni ssimo PrincipeD. T heodosio segundo D uquedeB ragança em Villaviç̧ssa na I greja dosreligi osos deS. Paul o primeiro hermitão ondeo di to senhor está depositado em 29 denovembro de 1630. Lisboa: M athias Rodrigues, 1632.0 sermão faz um elogio exaltado da Casa de Bragança declarando em uma passagem o seu expressivo posto no reino: "Tresgrandezas tem o Reyno dePortugal, com ser tão pequeno, \& limitado pera quem fora pequena aM onarchia Romana. Primeira a famosa cidade de Lisboa, cabeça do Reyno enchendo todas as partes do mundo com a opulencia de seus comercios, como sefora senhora do 0 ceano, como em outrostemposfoy [...] A segunda, as conquistas do Reyno. Senhoreando a monarchia portuguesa os berços dondeo sol nos nasce, $\&$ as sepulturas ondesenos esconde: dando principio ao seu senhorio, ondeaM onarchiaRomana posfim a seu imperio [...] A terceira, a magnificencia real da casa de Bragança, quea pos os Reys se segue, \& declara por tenção sua D epois devos, nos" 26v-27r.

${ }^{25} \mathrm{Cf}$. SCH WART Z Cit. p. 744-5.

${ }^{26}$ Joaquim Veríssimo Serrão, por exemplo, tratando das expedições holandesas sobreasconquistas de Portugal, refere-se à perda e recuperação da Bahia nos seguintes termos: " $\mathrm{Um}$ ataque de surpresa, em 1624, levou à conquista de Sal vador, notícia que ao chegar ao Reino causou a maior emoção. $\mathrm{N}$ o ano seguinte, uma frota enviada de Lisboa pôdereconquistar a capital do Brasil". SERRÃO , Joaquim Veríssimo. 0 tempo dosfilipesem Portugal eno Brasil (1580-1668). Lisboa: Colibri, 1994. Este texto foi publicado em 1982, num extenso manual deH istória dePortugal.

${ }^{27}$ GUERREIRO , Bartolomeu. Jornada dosVassalos, Cit. p. não numerada.

${ }^{28}$ VARGAS, TomásTamayo de. Retauracion d la ciudad D el Salvador, I Baia deTodos-Sanctos, em la província del Brasil por lãsarmasdeD om Philippel V, el grande, Rei Catholico delãsEspanas, Índiasetc. M adri: viúva deAlonso M artin, 1628, p. não numerada. Estelivro foi traduzido ao portuguêsededicado aD . Pedro II por I gnacio Accioli deC erqueiraeSilva em 1847.

${ }^{29}$ lbidem, p. não numerada.

${ }^{30}$ Ibidem, p. não numerada.

${ }^{31}$ A carta não saiu impressanaépoca. VIEIRA, Antônio. Cartas. Lisboa: Imprensa N acional, 1997, vol. I, p. 3-70.

32 VIEIRA, Op. Cit. p. 11.

${ }^{33}$ Felipell, apósa invasão dePortugal pelasforças castelhanas, fez reunir as cortes do reino em 1580. N a ocasião fez-se o acordo que, entre diversos outros itens, estatuía o princípio da nomeação de portugueses paraas funções de governo no reino (exceção aberta apenas parao Vice-Rei, semembro da família real) edo ultramar.

${ }^{34}$ M O ERBEECK, J an Andries. Redenen W âerommedeWest-Indisch Compagniedient tetrachten het Landt van Brasilia den Connick van Spangieteontmachtigen en data ten œrsten. Amsterdam: Cornelius L odewycksz, 1624. H átradução brasileira publicada com o título: 0 sholandesesno Brasil. Rio deJ aneiro, 1942. 
${ }^{35}$ N ARBO N A Y ZUÑ IG A, Eugenio de. "H istoriadela Recuperacion del Brasil". Anaisda Biblioteca N acional. Vol. 69, 1950, p. 170.

${ }^{36}$ GUERREIRO , p. 5.

${ }^{37}$ D entre as inúmeras edições desse texto, destaca-se a já citada de J osé M aria Viqueira Barreiro. 0 original de Lope deV ega acompanhado de longa introdução edecomentários nem sempredignos deconsideração.

${ }^{38}$ Entreas causas do descuido de $D$ iogo de $M$ endonça Furtado estaria o fato de "los governadores del siglo antes passan a ser mercadores que capitanes", FARIA E SO U SA, M anuel de. EpitomedelasH istoriasPortuguesas. Bruxelas: Foppens, 1677, p. 332.

${ }^{39}$ Epitome, p. 333.

${ }^{40}$ VALEN CIA Y GUZM ÁN , Juan de. Compendio historial dela jornada del Brasil año 1625. Recife: Pool, 1984, p.247.

${ }^{41}$ Compendio, p. 251.

${ }^{42}$ N ARBO N A Y ZUÑ IGA, Eugenio de. H istoria, p.191.

${ }^{43}$ VIEIRA, Cartas, p. 27.

${ }^{44}$ M EN EZES, M anuel de. "Recuperação da cidadedo Salvador", Revista do IH G B, 1850, p. 400.

${ }^{45}$ Plaineand TrueRelation, p. 9.

${ }^{46}$ ALD EN BU RG K, Johann G regor. Relação da Conquista, p. 178.

${ }^{47}$ ALDEN BU RGK K. Relação, p. 187.

48 “... setomo possession dela ciudad en nombre de D on Philipeel Q uarto Rei delasE spanas, entrando en ella el maestro de campo general, su teniente; i el maestro de campo $D$ on Juan de O rellana con algunascompañias para su guarda; como para la prevencion delo queconveniesse, ass en el modo deproceder delossoldados, comoen el cobro dela hazienda real..." VARGAS, Tomas Tamayo de. Recuperacion, p. 134r-v.

${ }^{49}$ VARG AS. Recuperacion, p. 134v-5r.

${ }^{50}$ Relaçam verdadeira detudo o succedido na restauração da Bahia detodos osSantos desdeo dia, em quepartirão asarmadasdesua $M$ agestade, téo em queem a dita Cidadeforão arvoradosseus etandartescom grandegl oria de D eos, exaltação do Rey, \& Reyno, nomedeseusvassallos, quenesta empresa seacharão, anihilação, \& perda dos O landezesali domados. M andada pellosofficiaesde sua M agetadea etesReynos Porto: João Rodriguez, 1625, p. não numerada. A data dataxação é12 de julho de 1625 e, conformeassegurou Pero Róis Soares, a notícia do sucesso chegou a 6 dejulho na capital. 0 documento foi reeditado depois em Lisboa. M aisrecentementeo IH BG publicou a relação no volume 5 de sua revista.

51 "Resolutas estas capitulações; deram os ol andeses a entrada na cidade, foram os primeiros queentraram, $0 \mathrm{M}$ arquês de Coprani eD. J oão de 0 relhana, aquem não tocavaa entrada, \& tocavaaAntônio M oniz Barreto, M estre deC ampo deum terço português". GU ERREIRO, Jornada, p. 58v. 
${ }^{52}$ GUERREIRO . Jornada, p. 59r.

${ }^{53}$ GUERREIRO . p. 58/59.

${ }^{54}$ M EN EZES. Recuperação, p. 592.

${ }^{55}$ M EN EZES. Recuperação, p. 591.

${ }^{56}$ M EN EZES. Recuperação, p. 592-3.

${ }^{57}$ VIEIRA. Cartas, p. 44.

${ }^{58}$ FARIA E SO USA. Epitome, p. 335.

${ }^{59}$ Plaineend TrueRelation, p. 20. ALD EN BU RG K. Relação: "I gualmente, tiveram queos portugueses de resgatar de novo a cidade deS. Salvador e pagar dobrado tributo anual ao tesouro espanhol... Além do mais, tiveram os portugueses deresgatar os seus velhos canhões em poder dosespanhóis, quemuito espoliaram a cidade, carregando os navios da frota com pau-brasil, fumo, açúcar, especiarias etudo quanto puderam arrebanhar demesas, cadeiras, tapeçariasemóveis", 218.

${ }^{60}$ CARN EIRO , D iogo G omes. O ração A podixica aos scismaticosda patria. Lisboa: Lourenço deAnvers, 1641, f. 8r.

${ }^{61}$ Seteanosapós os acontecimentos de Salvador, João Pinto Ribeiro publicou um livreto cujo título já expunha a resistência à idéia do empenho dos fidalgos portugueses nas guerras da M onarquia: D iscurso sobreosfidal gosesoldadosportuguesesnão militarem em conqui stasalheias desta coroa. Lisboa: Pedro C raesbeeck, 1632.

62 "T he council of Stateacted to prevent the publication beforeM enezes could publish his. See Consulta, Council of State, April 1623 [sic], British Library, London, Egerton 324, fol. 18". SCH WART Z. p. 740n.

\section{RESUMO}

A reconquista da cidade de Salvador pelas forças da M onarquia Católica em 1625 foi um grande feito bélico. A abundância de testemunhos, relatos e histórias da batalha são tantos elementos que certificam a importância do acontecido para seus contemporâneos. U m exame detido dessa literatura é capaz de mostrar uma oposi ção, ainda que dissimulada, entre fidalgos portugueses e castel hanos. eles dis putavam a proeminência nos feitos bélicos e a honra do desempenho vitorioso. Festejada, narrada e comemorada, a Batalha da Bahia acabou por se transformar num acontecimento revelador de tensões entre fidal gos de Portugal e de Castela, que iria alimentar uma dissensão mais que secular e que viria a tomar corpo em dezembro de 1640.

Palavras-chave: salvador, século XVII, narrativas históricas. 


\section{ABSTRACT}

The reconquering of the city of Salvador by the $C$ atholic $M$ onarquic Forces was a belic enterprise of great impact. The abundance of narrations, stories and live accounts of the battle testify to its importance for their contemporaries. A detailed exam of this literature shows the opposition, even if veiled, between the "Fidalgos" from Portugal and from Castela: they both claimed proeminence of belic achievements and the merit of victorious deeds. The Battle of Bahia, narrated and celebrated to great extent, turned out to be revealing of the tensions between the "fidalgos" of Portugal and Castela, which in turn would give rise to a discution more than secular eventually embodying itself in D ecember 1640.

Keywords: Salvador, XVII ${ }^{\text {th }}$ Century, historical narratives.

(recebido em julho de 2004 e aprovado em novembro do mesmo ano) 